\title{
Adolescent Empowerment through Life Skills Education
}

\author{
Mr. Sulfikar $C^{1 *}$
}

\section{ABSTRACT}

In the age of rapid globalization, industrialization, economic liberalization, expansion of information technology and rise in consumerism, the children and especially adolescents are exposed to lot of psycho social issues. Adolescents aged 10-19 years constitute about one-fourth of India's population and young people aged 10-24 years about one-third of the population. This large cohort of young people represents a great demographic dividend with the potential to contribute to India's economic growth and development. Violence and hostility are the hall marks of day today living and women and children are the worst affected section of the society. Changes in social, moral, cultural and religious values have made life stressful for children especially for adolescents. This can be observed in the rise of crime and suicide rates etc. Stress faced by children and adolescents are enormous and life skills are essentially those abilities that help to promote mental well-being and competence in young people for to challenge the diversities and ensure their empowerment. In order to realize this potential to the fullest, young people must be healthy, educated and equipped with information skills and confidence that would enable them to contribute to their communities and the country's socio-economic growth. In the present paper the investigator goes through the importance of life skills, various life skills and adolescent's empowerment through the life skills based education.

Keywords: Adolescents Empowerment, Life Skills, Life Skills Based Education (LSBE).

Adolescence marks the developmental transition from childhood to adulthood, a time when many important social, economic, biological, and demographic events set the stage for adult life. The nature and quality of young people's future lives, as well as a country's future social and economic development, depend largely on how well adolescents navigate this transition. In India, myriad social, economic, and health factors may undermine the ability of adolescents to lead full and productive lives. This is of particular concern given the sheer number of young people in India - an estimated 31\% (358 million) of national population is aged between 10-24 years and almost 19.6\% comprise of 10- 19 year olds Adolescents (236.5 million) (Office of the

\footnotetext{
${ }^{1}$ Doctoral Research Fellow (UGC JRF) in Social Work, Department of Social Work, Faculty of Social Science, Jamia Millia Islamia (A Central University), New Delhi, India

*Responding Author

(C) 2016 I C Sulfikar; licensee IJIP. This is an Open Access Research distributed under the terms of the Creative Commons Attribution License (http://creativecommons.org/licenses/by/2.0), which permits unrestricted use, distribution, and reproduction in any Medium, provided the original work is properly cited.
} 


\section{Adolescent Empowerment through Life Skills Education}

Registrar General and Census Commissioner of India 2011). It is well recognized that India's ability to achieve the Millennium Development Goals and to achieve its population stabilization goals will depend on the investment made in its young people. There has been political commitment by the government to meet the specific needs of the adolescent population. Policies have been put in place to ensure access to equitable education, reproductive health services and information targeted especially for adolescents; programmes initiated to provide nutrition to adolescents and laws enacted to protect the young from exploitation in the workplace or through trafficking. Adolescents today are healthier, better educated, and more aware; the average age at marriage has increased, and gender disparities in education attainment have declined. Despite these achievements, adolescents continue to be at a disadvantage and face barriers that restrict their access to resources, inhibit their ability to make informed choices about their life, limit access to education, employment opportunities, and access to reproductive health and care services. Life Skills Education is known as 'vaccine for mind' and 'vaccine for life' because it will help the adolescents and youth to prevent the occurrence of many psychosocial problems which they may encounter in future life. Life skills can be utilized in many areas like prevention of drug use, sexual violence, teenage pregnancy, HIV/AIDS prevention and suicide prevention etc. The life skill development extends into consumer education, environmental education, peace education or education for development, livelihood and income generation among others. In short, life skills empower young people to take positive action to protect them and promote health and positive social relationships. Self-awareness, self-esteem and self-confidence are essential tools for understanding one's strengths and weaknesses. Consequently, the individual is able to use available opportunities and prepare to face possible threats. Subsequently, through life skills are possible to identify problems that arise within both the family and society. With life skills, one is able to explore alternatives, weigh pros and cons and make rational decisions in solving each problem or issue as it arises. It also helps to establish productive interpersonal relationships with others. So it is the need of the age to impart life skills education in our adolescents that is life skill based education. Life skill education is a value added program which aims to provide students with strategies to make healthy choices that contribute to a meaningful life. It helps adolescents to understand their self and to assess their skills, abilities and areas of development. It also helps adolescents to get along with other people and adjust with their environment and making responsible decision. Life Skills Based Education (LSBE) refers to an interactive process of teaching and learning, which enables learners to acquire knowledge and to develop attitudes, and skills which are needed to make decisions, take decisions and take positive action to support the adoption of healthy behavior. The methods used to facilitate this active involvement include working in small groups and pairs, brainstorming, role play, games and debates etc. Hence life skills are essential to lead a successful life, which helps to cope and manage life situations. 


\section{Adolescent Empowerment through Life Skills Education}

\section{LIFE SKILLS}

UNICEF defines life skills as "a behavior change or behavior development approach designed to address a balance of three areas: knowledge, attitude and skills” and WHO also defines life skills as the "abilities for adaptive and positive behavior that enable individuals to deal effectively with the demands and challenges of everyday life"

WHO/UNICEF proposed ten core Life Skills. These Skills are classified as Thinking Skills/ Cognitive Skills, Social Skills and Negotiation Skills

\begin{tabular}{|l|l|l|}
\hline Thinking Skills/Cognitive Skills & \multicolumn{1}{|c|}{ Social Skills } & Negotiation Skills \\
\hline Self awareness & Interpersonal relationships & Coping with emotions \\
Creative thinking & Communication & Coping with stress \\
Critical thinking & Empathy & \\
Decision making & & \\
Problem solving & & \\
\hline
\end{tabular}

\section{1) Self Awareness}

We should have an awareness about ourselves that is self awareness, which means recognition of ourselves, our character, strength, weaknesses, desires and dislikes. A person may have dreams, visions, goals, etc. in his /her life which is also considered as a part of his self awareness. So the best way to understand our self awareness is to analyze our SWOT (Strength, Weakness, Opportunities and Threats). Every individual has innate abilities and potentials. It may vary from person to person. When we get an opportunity we can identify our strengths and weaknesses and try to overcome our limitations, reduce or remove our weaknesses by recognizing and developing our strengths.

Self-awareness is having a clear and realistic perception of who you are. Self-awareness is not about uncovering a deep dark secret about yourself, but understanding who you are. It is directly related to both emotional intelligence and success. It helps to create achievable goals because you can consider your strengths, weaknesses while setting your goals. It allow us to guide yourself in the right path by choosing the opportunities that are best fit for your skill-set, preferences and tendencies. It allows us to make positive behavioral changes that can lead to greater personal and interpersonal success

\section{2) Creative Thinking}

We can make a lot of products from a paper. Each one can develop a new item with a new idea like ship, aero plane, flower, etc. These kinds of divergent thinking are known as creative thinking, which help us to find out new ideas, look for choices and alternatives. Creative thinking contributes to both decision-making and problem solving by enabling us to explore the available alternatives and various consequences of our actions or non-action. It helps us to look beyond our direct experience and can help a person to respond most appropriately and adapt with

(c) The International Journal of Indian Psychology, ISSN 2348-5396 (e)| ISSN: 2349-3429 (p) | 158 


\section{Adolescent Empowerment through Life Skills Education}

flexibility to various situations/exigencies of daily lives. Creative thinking will help an adolescent to find out options to avoid various adolescent issues like negative peer pressure, addiction to drugs, Internet, TV etc and also find out new ways to better one study, time management, money management, use of different media etc.

\section{3) Critical Thinking}

You are travelling in a train. You are very thirsty. There is no drinking water in the compartment. You have a single choice to take either an orange or an apple. Which one will you select? Why did you select an orange? It is juicy, no need to wash, no need of a knife to cut it. We have analyzed the merits and demerits of the choice. There are positive and negative factors for each choice/option. The merit, demerit analysis of each option can be termed as critical thinking. Critical thinking is the ability to analyze information and experience in an objective manner. It contributes to both decision making and problem solving by exploring the available alternatives and their various consequences. It is helpful to the effective and responsible utilization of resources.

\section{4) Decision Making}

Decision-making helps us to deal constructively with our lives. It can be regarded as the cognitive process resulting in the selection of a course of action among several alternative scenarios. Every decision making process produces a final choice. POWER method for decision making,

- $\quad$ Problems (Describing and analyzing the problem objectively)

- Options (Alternatives/Choices identified with the help of creative thinking)

- Weighing (Positive, negative analysis of alternatives/choices; Critical analysis)

- $\quad$ Elect (Choosing the best alternative)

- $\quad$ Reflect (Reviewing the impact of decision)

Whenever you are required to take decisions, you may go through the above stages (POWER).You must strongly feel the problem which need to be solved, and then find out options, analyze critically and take decisions. Reflect or evaluate the decisions taken in an objective way to sustain the behavior to reach a problem solving level.

\section{5) Problem Solving}

Everyone experiences problems in life from time to time. Some of our problems are big and complicated while others are simple and can be easily solved. Problem solving refers to the ability to use knowledge, facts and data to solve problems effectively. This does not mean we need to have an immediate answer to it, it means we must think and assess problems and find solutions. Problem solving skills enable us to deal constructively with problems in our life but problems left unresolved can cause mental stress and give rise to physical strain. 


\section{Adolescent Empowerment through Life Skills Education}

\section{6) Communication}

Imagine that you are in a queue to take a railway ticket. A person comes from somewhere and stands in front of you in the queue. What will you do?

- $\quad$ Keep quiet? (Passive)

- $\quad$ Push him out? (Aggressive), or

- Tell him to follow the queue and ask him to go back? (Assertive)

Effective communication skills are required in our life cope with many situations. Assertive to communication is the skill required to overcome unfair pressure. It is the skill to say "NO" when a person feels strongly against a particular issue. Through saying 'NO' does not hurt the other person, it will make him feel how he had hurt you.We must be able to say 'No' when we feel that we are being pressurized to do something against our wishes. We must keep practising various techniques to say 'No' to get us out of difficult situations. Effective communication skills are very much essential for life. Effective Communication is a tool for healthy interpersonal relationships. To be an effective communicator we must learn to communicate assertively. Adolescents are exposed to various pressures. The kind of behaviour that adolescents adopt has a great impact on the relationship with peers. Thus, it is vital for adolescents to use productive assertive techniques when confronting peer pressure rather than developing behaviours that are passive or aggressive

\section{7) Interpersonal Relationships}

For good relationships we require certain qualities like mutual understanding, respect, etc. No matter how hard you work or how brilliant you are, if you can't connect with the people who work around, your life will suffer. Interpersonal skills help us to relate with others in a positive manner. The best relationship results from both people contributing the positive qualities like mutual respect, trust, freedom, love, kindness, and understanding. There are various types of relationships present among the people. Keeping healthy relationships is very much essential for success in life. An interpersonal relationship is a strong, deep or close association between two or more people that may range in duration from brief to enduring. This association may be based on inference, love, solidarity or some other type of social commitment. Interpersonal relationships are formed in the context of social, cultural and other influences. The context can vary from family or kinship relations, to friendship, marriage, relation with associates, neighborhoods, etc. They may be regulated by law, custom or mutual agreement and are the basis of social groups and society as a whole. Adolescents require understanding the problems in risky/ unhealthy relationships. Peer relationships have both positive and negative influence on adolescents. Peer groups have a significant influence on psychological and social adjustments that are required by groups and individuals. Peer groups provide perspective outside of individual's viewpoints. Members inside peer groups also learn to develop relationships with others in the social system. Peer group relations are more important during the adolescence period. Most adolescents are deeply involved with their peer group. The teenagers look for their group for approval, and may even change their behavior to win the social approval. Peer pressure

(C) The International Journal of Indian Psychology, ISSN 2348-5396 (e) | ISSN: 2349-3429 (p) | 160 


\section{Adolescent Empowerment through Life Skills Education}

has both positive and negative effects. The negative influence of peer pressure may disorient their personality and take them too many antisocial activities.

\section{8) Empathy}

If you analyze the venue of a accident, you can see people with different behaviors, One person may not respond any way to that situation and other one may come forward and say. Oh, poor, it is his/her fate. Another person may take him to the hospital and provide necessary support. The first person was not interested in helping the person, not even ready to be sensitive to the situation- Apathy. The Second person has sympathized with the situation, just making some comments - Sympathy. The third person was involved in helping the victim by taking him to the hospital-Empathy

Empathy is the ability to understand and accept others as they are, that is being nurturing and tolerant. It helps an individual to understand and accept others who may be very different from himself and improves social interactions. Empathy is feeling with others and helping them. It is essential for the developing of love, kindness and social responsibility. It encourages a positive behavior towards people in need of support, care and assistance and avoids stigmatized behavior. Empathy is the better understanding of the emotional status of other people without losing one's own emotional status.

\section{9) Coping With Emotions}

Anger is an automatic response to ill-treatment. Anger can be caused by both external and internal factors. The external expression of anger can be found in facial expressions, body language, physiological responses, and at times in public acts of aggression. Humans and animals for example make loud sounds, attempt to look physically larger, bare their teeth, and stare. Emotions are both constructive and destructive. Positive emotional status will help to obtain mental health. Negative emotions create various health problems (Physical and mental health issues). Emotions are essential for human life. Emotional experiences vary from one individual to another and from one situation to another. Emotions /feelings have both positive and negative effects. Unpleasant emotions like fear, anger, and jealousy may harm one, damage friendship, affect learning, disturb family relationships, team work etc. The following stages are useful to control our emotions

1. Identify your emotion

2. Analyze why the situation bothers you.

3. Analyze the effect; the situation can have on your life.

4. Decide what you can and cannot change

5. Choose a positive way to react

6. Think of something positive, you can learn from the situation 


\section{Adolescent Empowerment through Life Skills Education}

Adolescents require proper emotional adjustments. They are more vulnerable to emotional problems due to various physiological and psychological changes. Adolescence is a period which tries to experience various emotions to reach emotional maturity. Hormones have great influence on up the emotional expressions of adolescents.

\section{0) Coping With Stress}

Anything that poses a challenge or a threat to our well being is a stress. Some stresses get you going and they are good for you. However when the stresses undermine both our mental and physical health they are bad. Adolescents are more susceptible to stress. Adolescents are facing many stressful situations in modern days. They could not cope with many unpleasant situations. The stress may be also due to the lack of adjustment with physical and psychological changes. Family tension, academic pressure, peer pressure etc heighten the stress and strain among adolescents. Stress is the state of physical or psychological strain which imposes demands for adjustments upon the individual. The young adolescents are requiring to developing appropriate strategies to cope with stress. Coping with Stress is about recognizing the source of stress in our lives recognizing how these affect one and acting in ways that help to control the level of stress. So adolescence has to follow certain habits in their daily life to cope with stress, like Exercise regularly, Eat a healthy diet, Reduce caffeine and sugar, Avoid alcohol, cigarettes, and drugs, get enough sleep etc. Coping with Stress is about recognizing the source of stress in our lives, recognizing how these affect one and acting in ways that help to control the level of stress. It also means learning how to relax so that tensions created by unavoidable stress do not give rise to health issues.

\section{CONCLUSION}

Life skills and life skill based education is help adolescents to deal effectively with real life situations. Adolescents require analytical skills to make decisions, solve problems, become aware of their strengths and weaknesses, set certain goals for themselves, and to gear their efforts towards achieving these goals. Social skills help adolescents establish positive relationships with other people and help them in communicating effectively with peers, adults and others in the society. Negotiating skills are required to resist peer pressures, temptations and to make mutual compromises. And through the life skills based education (LSBE) our younger generation will empower and it leads to the development of the nation.

\section{BIBLIOGRAPHY:}

Adolescent Education Programme, Ministry Of Human Resource Development, Government of India http://mhrd.gov.in/adolesence_education

Bandura, A. (1977). Social Learning Theory. Englewood Cliffs, NJ: Prentice-Hall.

Botvin, G.J., Eng, A. and Wlliams, C.L. (1980). Preventing the onset of cigarette smoking through Life Skills Training. Preventive Medicine, 11, 199-211 


\section{Adolescent Empowerment through Life Skills Education}

Caplan; M., Weissberg, R.P., Grober, J.S., Jacoby, C. Social competence promotion with inner city and suburban young adolescents: effects on social adjustment and alchohol use. Journal of Consulting and Clinical Psychology, 1992, 60 (1), 56-63.

http://www.censusindia.gov.in/vital_statistics/SRS_Based/SRS_Based.html

Pentz, M.A. Prevention of adolescent substance abuse through social skills development. In Glynn, TJ.et al. (Eds.) Preventing adolescent drug abuse: Intervention strategies, NIDA Research Monograph, 1983, No 47,195-235.

TACADE. Skills for the Primary School Child: Promoting the Protection of Children. UK:Salford,1990

Weissberg, R.P., Caplan, M.Z. and Sivo, P.J. A new conceptual framework for establishing school-based social competence promotion programs. In Bond. L.A. and Compas. B. E. (Eds.) Primary prevention and promotion in schools. Newbury Park, CA: Sage, 1984

World Health Organization. Life skills education: planning for research. Geneva, WHO, 1996.72p.

How to cite this article: C Sulfikar (2016), Adolescent Empowerment through Life Skills Education, International Journal of Indian Psychology, Volume 3, Issue 3, No. 10, DIP: 18.01.189/20160303, ISBN: 978-1-365-19879-3 